\title{
Typology of the antegonial notch in the human mandible
}

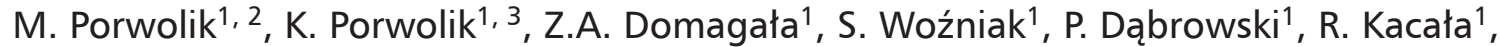 \\ H. Kordecki1, 4, P. Chmielewski ${ }^{1}$, S. Abu Faraj ${ }^{1}$, B. Gworys ${ }^{1}$ \\ ${ }^{1}$ Department of Anatomy, Wroclaw Medical University, Wroclaw, Poland \\ ${ }^{2}$ Non-public Medical College, Wroclaw, Poland \\ ${ }^{3}$ Public Medical Training College, Opole, Poland \\ ${ }^{4}$ Institute of Computer Engineering, Control and Robotics, Wroclaw University of Technology, Wroclaw, Poland
}

[Received 30 June 2014; Accepted 16 November 2014]

Background: Surgical treatment for serious malocclusions and fractures of the organ of mastication is a golden standard in medicine. Procedures performed on the mandible require detailed knowledge of the anatomy of the organ. Antegonial notching constitutes a serious technical challenge for surgeons. Therefore, a detailed anatomical description of this structure, which is the subject of this paper, is essential. Materials and methods: We analysed 251 human Caucasian mandibles of identified sex and took measurements of all sections describing the mandibular antegonial notch. Depending on the proportion between sections we classified the shape of the antegonial notch into three types. The surface area of the notch was calculated. We analysed the dimorphic and bilateral differences for each of the three types of notch. We used variance analysis for the assessment of statistical difference.

Results: The analysis revealed that in both men and women, regardless of body side, the type 3 antegonial notch was the most frequent. Type 3 occurred with a frequency of between 38\% in men on the right side and $55.9 \%$ in women on the left side of the body. Type 1 was the least frequent. Dimorphic differences in the presence of individual types of antegonial notch were statistically significant only for the left side of the body. The symmetrical type (type 2) occurred more frequently in men (by 11\%) than in women. Type 3 was found more frequently in women (by 10\%) than in men. Bilateral differences in men were revealed for the frequencies of types 1 and 3. On the right side type 1 was more frequent (by $8 \%$ ), and on the left side type 3 was also more frequent (by $8 \%$ ). The greatest surface area was found for the asymmetrical posterior type (type 1). The smallest surface area was found for the asymmetrical anterior type 3. This difference was statistically significant with respect to the surface area of types 1 and type 2 and found for both sexes for both sides of the body. However, no statistically significant differences were found between the surface areas of types 1 or 2.

Conclusions: Knowledge of the preangular notch anatomy can be useful for surgeons during reconstructive and plastic procedures on the body of the mandible. (Folia Morphol 2015; 74, 3: 365-371)

Key words: mandible anatomy, antegonial notch, variance analysis.

Address for correspondence: Dr Z. Domagała, Department of Anatomy, Wroclaw Medical University, ul. Chalubińskiego 6a, 50-367 Wrocław, Poland, tel: +48 7178413 40, e-mail: zygmunt.domagala@umed.wroc.pl 


\section{INTRODUCTION}

The antegonial notch is present on the lower margin of the mandibular body, at the junction between the ramus and the body of the mandible, immediately anterior to its angle. Maclntosh [13] defined it as the "pregonial notch", and Henderson and Poswillo [8] described it as the "antegonial notch". The presence of the antegonial notch was reported by various researchers $[2,10,17,19,20]$. Information on the presence, location and depth of this notch is important for maxillofacial surgeons during orthognathic treatment of mandibular deformities [16, 22].

Advances in medical diagnostic methods aim at the optimal assessment of a patient's health using the least invasive techniques. Therefore, there is an urgent need to define a 'standard' which would describe a certain diagnostic procedure. A perfect solution for this would be a method that is simple but offers the highest possible sensitivity and specificity. Many techniques have been used for the surgical treatment of mandibular deformities. Currently, most of these surgical procedures are performed using an intraoral approach, with a sagittal split of the mandibular ramus by Dal Pont and its subsequent modifications being the most popular [6, 7, 22]. An operator cutting the outer cortical layer of the mandibular body at the height of the molars after subperiosteal introduction of the lower part of a hooked tool into the base of the mandible (near the first molar) may encounter difficulties in moving the tool in the rear direction, towards the gonial angle. The preoperative analysis of the lower margin of the mandibular body in each patient indicates that in some cases there is a variable size notch on the mandibular base, whose posterior dorsum may block the distal movement of the tool.

The aim of our study was to analyse the variability of the shape of the mandibular antegonial notch and to present its typology based on the obtained results. We also analysed the differences in the frequency of identified types depending on the sex and body side.

\section{MATERIALS AND METHODS}

The analysis included 251 human Caucasian, European mandibles (158 males and 93 females). For each mandible detailed measurements of the antegonial notch were taken. We grouped results in terms of sex and body side (right and left). We analysed the length of sections $A B, A D, D B$, and $D E$ (Fig. 1), and then calculated the surface area for each triangle.

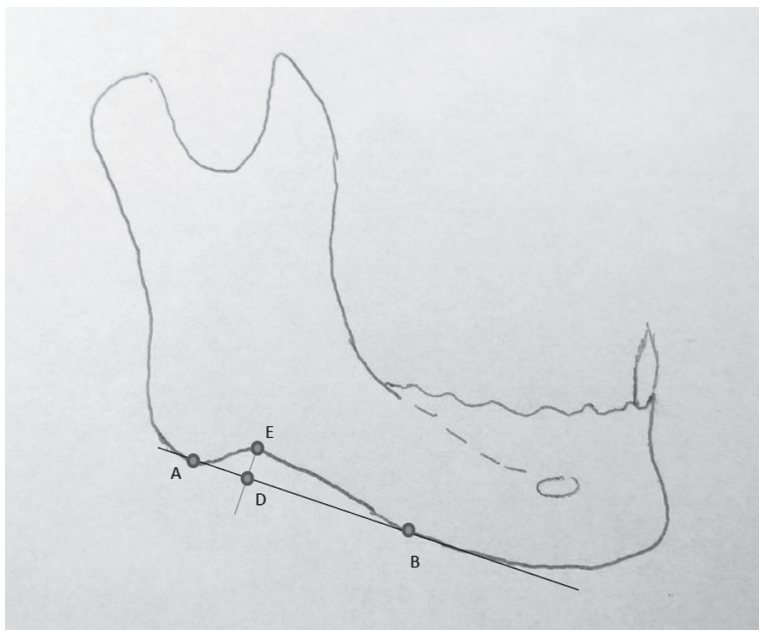

Figure 1. Measured sections of the mandibular antegonial notch; A - distal border of the antegonial notch; B - proximal border of the antegonial notch; E - fundus of the antegonial notch; D extrapolated point of the position of the antegonial notch fundus at its basis.

Selection of the measurement points was the result of direct contact between doctors and surgeons. The chosen measurement points allow, if necessary, taking identical measurements in vivo. Depending on the proportion between sections $A B, A D$ and $D B$ we classified the shape of the antegonial notch into three types:

- type $1-A D<0.3 \times A B$;

- type $2-0.3 \times A B \leq A D<0.4 \times A B$;

- type $3-\mathrm{AD} \geq 0.4 \times \mathrm{AB}$.

Digital calliper Mitutoyo 500-752-10, with CE and Tüv certificates was used for metric measurements. Photos were taken using a Sony digital camera set on a tripod, which ensured the same position of each examined mandible against the camera.

We have chosen the simplest measurement methodology, in order to ensure easy repetitiveness of the technique and allow measurements performed on $X$-rays and computed tomography imaging without the need for refined measuring program.

The surface area of the mandibular antegonial notch was approximated based on the shape and surface area of the triangle it formed. We identified three types of triangles, presented in Figures 2-5. According to this classification we distinguished three types of antegonial notch. Type 1 was defined as the asymmetrical posterior notch; type 2 - the symmetrical notch; type 3 - the asymmetrical anterior notch. It should be pointed out that in the symmetrical type, the length of the $A D$ section equals that 


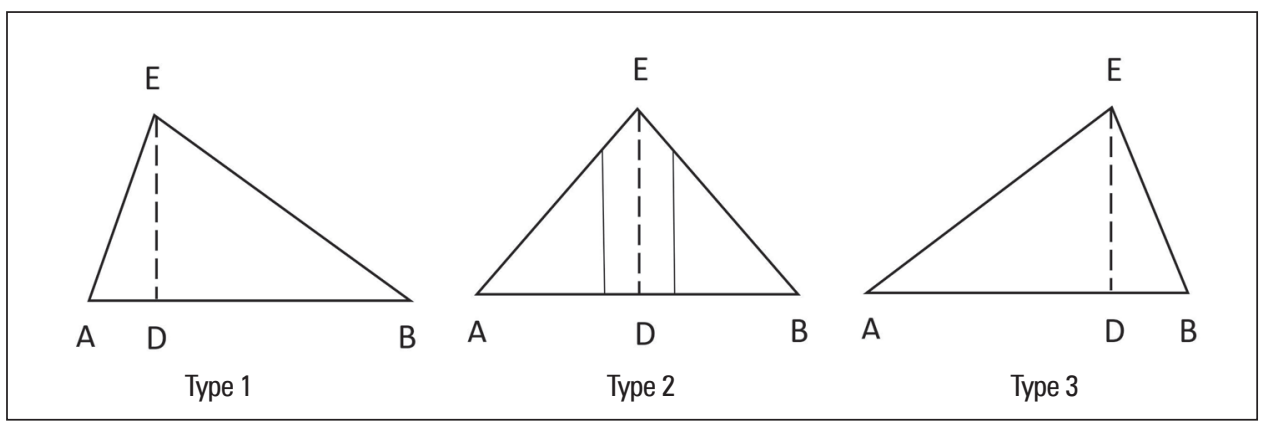

Figure 2. Types of mandibular antegonial notch; Type 1 - asymmetrical posterior notch; Type 2 — symmetrical notch; Type 3 - asymmetrical anterior notch.

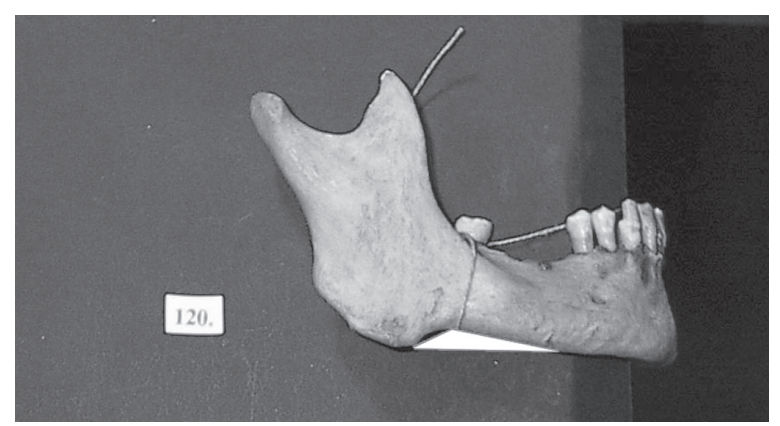

Figure 3. Asymmetrical posterior notch (type 1).

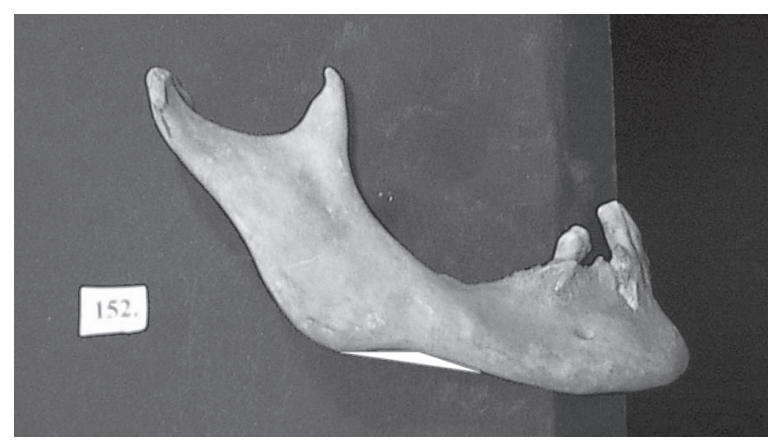

Figure 4. Symmetrical notch (type 2).

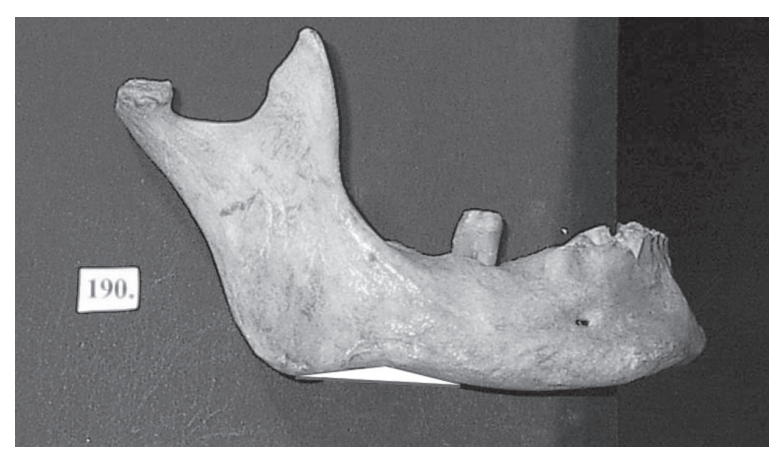

Figure 5. Asymmetrical anterior notch (type 3). of the DB section. However, we deliberately accepted a tolerance of $\pm 1 \mathrm{~mm}$ for the difference between both sections; otherwise, the data set for such cases would be empty. With this approach the classification took into account the distribution of values for the analysed parameters and ensured an appropriate sample size.

Measured values were analysed with statistical methods using one-way variance analysis (ANOVA). We also analysed the differences in the frequency of the identified types in both sexes on both body sides. The significance of dimorphic and bilateral differences between individual groups was evaluated by comparing the surface area of triangles characteristic for the identified types.

\section{RESULTS}

The analysis revealed that in both men and women, regardless of the body side, most mandibular antegonial notches were classified as type 3 (Table 1). This asymmetrical anterior type is characterised by the gentle line of the posterior part of the notch, which suggests a low probability of difficulties in the use of the Dal Pont surgical technique. Type 3 was found in $38 \%$ of men on the right side and in $55.9 \%$ of women on the left side of the body.

The lowest frequency was found for type 1 (asymmetrical posterior type), in which the posterior part of the antegonial notch has a high angle. This type of antegonial notch predisposes to difficulty in performing surgery by the Dal Pont technique. Type 1 was found in $17.1 \%$ of men on the left side and in $25.3 \%$ of men on the right side of the body.

Dimorphic differences in the presence of individual types of antegonial notch were statistically significant only for the left side of the body, and the symmetrical type (type 2) occurred more frequently 
Table 1. Frequency (N) of individual types of antegonial mandibular notch

\begin{tabular}{lccccc}
\hline & & Male & & & \multicolumn{2}{c}{ Female } \\
\cline { 2 - 3 } \cline { 5 - 6 } & Left & Right & & Right & Left \\
\hline Type 1 & $40(25.3 \%)$ & $27(17.1 \%)$ & & $23(24.7 \%)$ & $17(18.3 \%)$ \\
Type 2 & $58(36.7 \%)$ & $58(36.7 \%)$ & & $29(31.2 \%)$ & $24(25.8 \%)$ \\
Type 3 & $60(38.0 \%)$ & $73(46.2 \%)$ & & $41(44.1 \%)$ & $52(55.9 \%)$ \\
Total & $158(100 \%)$ & $158(100 \%)$ & & $93(100 \%)$ & $93(100 \%)$ \\
\hline
\end{tabular}

Type 1 - asymmetrical posterior notch; Type 2 - symmetrical notch; Type 3 - asymmetrical anterior notch

Table 2. Surface area of the distinguished types of mandibular antegonial notch

\begin{tabular}{|c|c|c|c|c|c|c|c|c|}
\hline & \multicolumn{4}{|c|}{ Male } & \multicolumn{4}{|c|}{ Female } \\
\hline & \multicolumn{2}{|c|}{ Right } & \multicolumn{2}{|c|}{ Left } & \multicolumn{2}{|c|}{ Right } & \multicolumn{2}{|c|}{ Left } \\
\hline & $\begin{array}{c}\text { Surface } \\
\text { area }\end{array}$ & $\mathbf{N}$ & $\begin{array}{c}\text { Surface } \\
\text { area }\end{array}$ & $\mathbf{N}$ & $\begin{array}{c}\text { Surface } \\
\text { area }\end{array}$ & $\mathbf{N}$ & $\begin{array}{c}\text { Surface } \\
\text { area }\end{array}$ & $\mathbf{N}$ \\
\hline Tyрe 1 & 58.98 & 40 & 46.25 & 27 & 49.72 & 23 & 36.76 & 17 \\
\hline Tyрe 2 & 54.32 & 58 & 46.98 & 58 & 46.31 & 29 & 39.87 & 24 \\
\hline Tyрe 3 & 30.14 & 60 & 34.76 & 73 & 32.14 & 41 & 31.73 & 52 \\
\hline Total & & 158 & & 158 & & 93 & & 93 \\
\hline
\end{tabular}

Type 1 - asymmetrical posterior notch; Type 2 - symmetrical notch; Type 3 - asymmetrical anterior notch

in men (by $11 \%$ ) than in women. Type 3 was found more frequently in women (by $10 \%$ ) than in men.

Bilateral differences in men were revealed for the frequencies of types 1 and 3. On the right side type 1 was more frequent (by $8 \%$ ), and on the left side type 3 was also statistically more frequent (by $8 \%$ ). It should be kept in mind that type 1 predisposes to difficulties in performing sagittal osteotomy of the mandibular ramus, and was found in $17.2 \%$ of men on the left side of the body. In women type 1 was found on the left side (18.3\%) and on the right side of the body (24.7\%).

In the second stage of the study we measured the surface area of the mandibular antegonial notch for the previously identified types (Table 2, Figs. 6-9). Information on the surface area will help to make additional assessment of difficulties in performing sagittal osteotomy of the mandibular ramus. When the surface area is smaller difficulties are less likely to occur. The asymmetrical posterior type (type 1) is characterised by the largest surface area, and its presence may suggest greater difficulties in performing procedures. The surface area for type 1 was $58.98-46.25 \mathrm{~mm}^{2}$ in men and $49.72-36.76 \mathrm{~mm}^{2}$ in women.

Table 3 presents results from variance analysis with significance levels for differences between the identified types of antegonial notch. The smallest surface area was found for the asymmetrical anterior type (type 3). Variance analysis demonstrated that this difference was statistically significant when compared to the surface area of types 1 and 2 . This difference was found for both sexes for both sides of the body. However, no statistically significant differences were found between the surface areas of types 1 or 2 .

\section{DISCUSSION}

The mandibular antegonial notch has been studied and analysed in the aspect of craniofacial morphology. Singer et al. [18] carried out a 4-year continuous study of 25 orthodontically treated patients and found, based on radiographs, that deep notch cases had more retrusive mandibles with a shorter body, smaller ramus height, and a greater gonial angle than did shallow notch cases. During the examined period the deep notch patients experienced a smaller increase in total mandibular length and body length, and less displacement of the chin in a horizontal direction (and thus had more retrusive mandibles) than did the shallow notch subjects. Singer et al. [18] also found that patients with a deep mandibular notch had a longer total and lower facial height. During the study period the depth of the notch increased in the deep notch subjects and decreased in the shallow notch subjects. The results of this study suggested that the presence of a deep antegonial notch was 


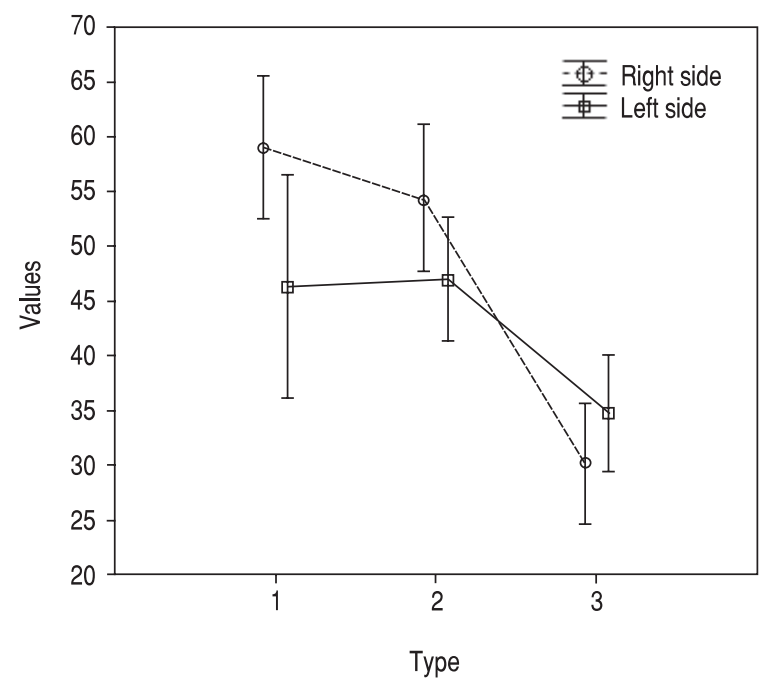

Figure 6. Surface area of individual notch types in males, on the right and left sides.

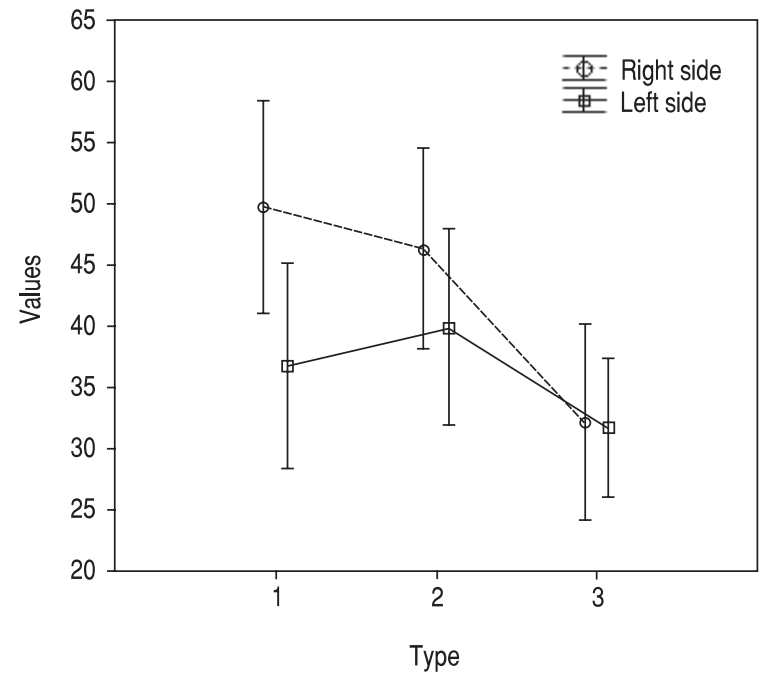

Figure 7. Surface area of individual notch types in females, on the right and left sides.

indicative of a diminished mandibular growth potential and a vertically directed mandibular and facial growth pattern. From the practical point of view, it is also important that deep notch patients required longer orthodontic treatment than shallow notch cases. Similar conclusions were also made by various scientists who indicated that deep notch mandibles have lower antero-posterior length and experience less growth, as well as less intense growth of the condylar process $[2-5,9]$. Lambrechts et al. [12], Wu

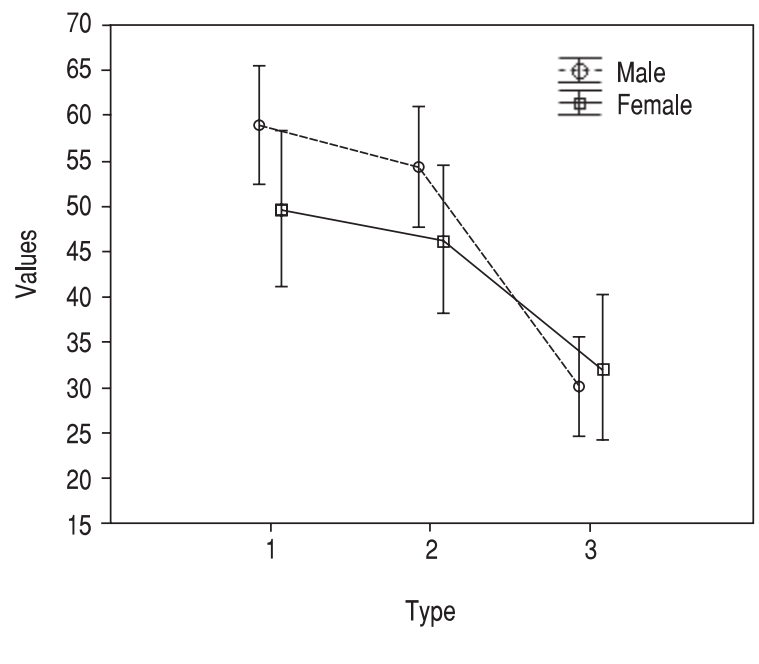

Figure 8. Surface area of individual notch types in males and females on the right side.

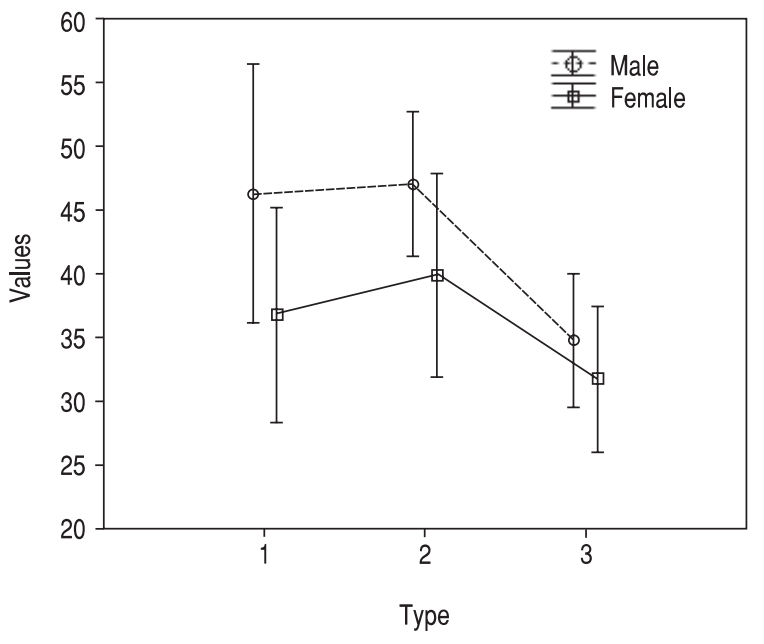

Figure 9. Surface area of individual notch types in males and females on the left side.

and Zhang [23] and Zhang et al. [24] pointed out the greater angle of the occlusal plane, the greater value of the gonial angle and the greater frontal facial height. Based on these reports most researchers claimed that the deep mandibular antegonial notch is indicative of a diminished mandibular and facial growth potential. However, Kołodziej et al. [11] carried out a continuous study on 40 subjects aged 8-17 years, with no treatment history and examined three times, and concluded that the depth of the 
Table 3. Results of variance analysis

\begin{tabular}{lccc}
\hline & Type of shape & $\mathbf{2}$ & $\mathbf{3}$ \\
\hline Male & & & \\
Right side & 1 & $\mathrm{P}=0.305$ & $\mathrm{P}=0.000(-)$ \\
& 2 & & $\mathrm{P}=0.000(-)$ \\
Left side & 1 & $\mathrm{P}=0.890$ & $\mathrm{P}=0.024(-)$ \\
& 2 & & $\mathrm{P}=0.002(-)$ \\
\hline Female & 1 & $\mathrm{P}=0.554$ & $\mathrm{P}=0.002(-)$ \\
Right side & 2 & & $\mathrm{P}=0.000(-)$ \\
& 1 & $\mathrm{P}=0.635$ & $\mathrm{P}=0.003(-)$ \\
Left side & 2 & & $\mathrm{P}=0.002(-)$ \\
\hline
\end{tabular}

Type 1 - asymmetrical posterior notch; Type 2 - symmetrical notch; Type 3 - asymmetrical anterior notch

antegonial notch is an insufficient indicator of facial growth potential. Tomer and Kishani [20] also found no statistically significant correlation between the craniofacial morphology and depth of the notch. Studies by Salem et al. [17] on the surface area of the antegonial notch demonstrated that larger surface area was associated with a trend for greater vertical direction of mandibular growth. They also found that the depth of the curve of Spee describing occlusion, and the length of the mandibular body decreases with increasing surface area of the antegonial notch. Ali et al. [1] found that patients with bilateral condylar bone changes and disorders of the temporomandibular joints had a smaller ramus height and a shorter mandibular body, but also a deeper antegonial notch and mandibular notch. Thus, the results suggested that condylar bone changes may be associated with mandibular dimensions, but also with the depth of the antegonial notch and mandibular ramus. Osato et al. [15] studied 37 radiographs of mandibles from a Japanese cranial collection and analysed differences in the morphology of the mandibular body by assessing the morphometric parameters and mineralisation degree before and after the eruption of the third molar. The results of their study indicated that differences in the posterior length of the mandibular body and mineralisation degree were significantly greater in samples with erupted third molar and low values of gonial angle. Nakajima and Osato [14] analysed 19 radiographs and found differences in the morphology and bone mineral content between subjects with a low $\left(<120^{\circ}\right)$ and high $\left(>125^{\circ}\right)$ gonial angle. Subjects with a low gonial angle had a significantly deeper antegonial notch and a wider lower cortical width in the assessment of bone mineral content. Similar findings on the depth of the antegonial notch and angle and bone mineral content depending on the gonial angle size were presented by Osato et al. [15]. Results from the studies by Japanese researchers on the correlation between the depth of the antegonial notch and the length of the mandibular body and gonial angle size contradict findings by the previously presented researchers. There are also reports on the correlation between masseter muscle activity and the depth of the antegonial notch [2,9]. Tomer and Kishani [20] tested masseter muscle activity in 90 subjects. The subjects were divided into three groups: with shallow, moderate and deep notches. The results demonstrated a positive correlation between the increased activity of the masseter muscle and the depth of the antegonial notch. Information on the morphology of the antegonial notch is also important for planning and performing maxillofacial and plastic surgical procedures in patients with facial asymmetry $[10,21]$.

The presented reports indicate that the antegonial mandibular notch has been analysed only in terms of its depth and classified as deep or shallow. Results from our study provide more detailed information on the antegonial notch, as we present its typology based on shape and size. Even though our classification is slightly more complex, it carries more clinical significance. Experienced craniomaxillofacial surgeons pay attention to more than just the depth of the incision. When manoeuvring the surgical tools, knowing the total length of the incision and the ratio of total length [section $A B$ ] to the actual length of the anterior, sharper foramen of the notch [section $A E$ ] or to the extrapolated length of that foramen [section AD]. As that is where the surgeon may come across technical difficulties during a surgical procedure.

\section{CONCLUSIONS}

Our analysis revealed that in both men and women, regardless of the body side, most mandibular antegonial notches can be classified as the asymmetrical anterior type. Type 3 occurs in $38 \%$ of men on the right side and in $55.9 \%$ of women on the left side of the body. The lowest frequency was found for the asymmetrical posterior type (type 1). It occurs in men with a frequency between $17.1 \%$ on the left side and $25.3 \%$ on the right side of the body. Dimorphic differences in the presence of individual types of man- 
dibular antegonial notch were statistically significant only for the left side of the body. The symmetrical type (type 2) occurred more frequently in men (by $11 \%$ ) than in women. Type 3 was found more frequently in women (by 10\%) than in men. Bilateral differences in men were revealed for the frequencies of types 1 and 3. On the right side type 1 was more frequent (by $8 \%$ ), and on the left side type 3 was also statistically more frequent (by $8 \%$ ). Type 1 occurs in $18.3 \%$ of women on the left side and in $24.7 \%$ of women on the right side. The largest surface area was found for the asymmetrical posterior type (type 1 ). The surface area for type 1 was $58.98-46.25 \mathrm{~mm}^{2}$ in men and $49.72-36.76 \mathrm{~mm}^{2}$ in women. The smallest surface area was found for the asymmetrical anterior type (type 3). This difference was statistically significant with respect to the surface area of type 1 and type 2 . The difference was found for both sexes for both sides of the body. However, no statistically significant differences were found between the surface areas of types 1 and 2.

\section{REFERENCES}

1. Ali JM, Yamada K, Hanada K (2005) Mandibular antegonial and ramus notch depths and condylar bone change. J Oral Rehabil, 32: 1-6.

2. Becker MH, Coccaro PJ, Conversc MD (1976) Antegonial notching of the mandible: an often overlooked mandibular deformity in congenital and acquired disorders. Radiology, 121: 149-151.

3. Bjork A, Skeiller V (1983) Normal and abnormal growth of the mandible: a synthesis of longitudinal cephalometric implant studies over a period of 25 years. Eur J Orthod, 5: 1-46.

4. Brodie AG (1941) Behavior of normal and abnormal facial growth patterns. Am J Orthod, 27: 633-647.

5. Chole RC, Ranjitkumar NP, Swati BC, Gondivkar S, Gadbail AR, Yuwanati MB, (2013) Association of Mandible Anatomy with age, gender and dental status: a radiographic study. ISRN, Radiology Article ID: 453763.

6. Dal Pont G (1961) Retromolar osteotomy for the correction of prognathism. J Oral Surg Anesth Hosp Dent Serv, 19: 42-47.

7. Epker BN (1977) Modifications in the sagittal osteotomy of the mandible. J Oral Surg, 35: 157-159.

8. Henderson D, Poswillo D (1985) A colour atlas and textbook of orthognathic surgery. The surgery of facial skeletal deformity. Wolfe Medical Publications Ltd., Weert.

9. Hovell JH (1965) Variations in mandibular form. Ann R Coll Surg Engl, 37: 1-18.

10. Kaczkowski H, Porwolik K, Porwolik M, Noga L, Woytoń H, Domagała Z, Gworys B (2012) Anatomical analysis of preangular mandibular notch in humans. Folia Morphol, 71: 100-104.

11. Kołodziej RP, Southard TE, Southard KA, Casko JS, Jakobsen JR (2002) Evaluation of antegonial notch depth growth prediction. Am J Orthod Dentofacial Orthop, 121: 357-363.

12. Lambrechts AHD, Haris AMP, Russouw PE, Stander J (1996) Dimensional differences in the craniofacial morphologies of groups with deep and shallow mandibular antegonial notching. Angle Orthod, 66: 265-272.

13. MacIntosh RB (1981) Experience with the sagittal osteotomy of the mandibular ramus. A 13-year review. J Maxillofac Surg, 9: 151-165.

14. Nakajima S, Osato S (2013) Association of gonial angle with morphology and bone mineral content of the body of the adult human mandible with complete permanent dentition. Ann Anat, 195: 533-538.

15. Osato S, Kuroyama I, Nakajima S, Ogawa T, Misaki K (2012) Differences in 5 anatomic parameters of mandibular body morphology by gonial angle size in dentulous Japanese subjects. Ann Anat, 194: 446-451.

16. Park KR, Kim S, Kim GJ, Park HS, Jung YS (2013) Anatomic study to determine a safe surgical reference point for mandibular ramus osteotomy. J Craniofac Surg, 42: 22-27.

17. Salem OH, Al-Sehaibany F, Preston CB (2003) Aspects of mandibular morphology, with specific refrence to the antegonial notch and the curve of Spee. J Clin Pediatr Dent, 27: 261-265.

18. Singer CP, Mamandras AH, Hunter WS (1987) The depth of the mandibular antegonial notch as an indicator of mandibular growth. Am J Orthod Dentofacial Orthop, 91: 117-24.

19. Takahiro O, Shigeo O (2013) Growth changes of the mandibular body with eruption of mandibular third molars: Analysis of anatomical morphometry and quantitative bone mineral content by using radiography. Ann Anat, 195: 143-150.

20. Tomer G, Kishani R (2011) Correlation of antegonial notch depth with craniofacial morphology a cephalometric and electromyographic study. J Pieere Fauchard Acad, 25: 163-171.

21. Uribe F, Janakirman N, Shafer D, Manda R (2013) Three-dimensional cone-beam computed tomography-based virtual treatment planning and fabrication of a surgical splint for asymmetric patients: surgery first approach. Am J Orthod Dentofacial Orthop, 144: 748-758.

22. Wolford LM (2000) The sagittal split ramus osteotomy as the preferred treatment for mandibular prognathism. J Oral Maxillofac Surg, 58: 833-839.

23. Wu JY, Zhang M (2001) A comparative study of craniofacial morphologic differences between groups with shallow and deep antegonial notch depth. Shanghai Kou Qiang Y Xue, 10: 217-220.

24. Zhang M, Zhao Q, Chen YX (2006) Dimensional differences in craniofacial morphologies of prepubence Class II patients with deep an shallow mandibular antegonial notching. Hua Xi Kou Qiang Yi Xue Za Zhi, 24: 142-145.. 